\title{
Collaboration between In-Service School Teachers and Families in the Context of Inclusive Education: A Review of the Recent Literature
}

\author{
Spyridon Kazanopoulos ${ }^{1 *}(\mathrm{PhDc})$ Maria Mouchritsa ${ }^{1}(\mathrm{PhDc})$ Eneko Tejada Garitano ${ }^{2}$ \\ Xabier Basogain Olabe ${ }^{3}$ \\ 1.University of the Basque Country, UPV/EHU, Spain \\ 2.Department of Didactics and School Organization, University of the Basque Country, UPV/EHU, Leioa \\ (Bizkaia), Spain \\ 3.Department of Automatic and Systems Engineering, University of the Basque Country, UPV/EHU, Leioa \\ (Bizkaia), Spain
}

\begin{abstract}
Collaboration between teachers and parents of children with and without disabilities is one of the key essential elements to ensure effective inclusive education. The purpose of this literature review paper is to examine international empirical studies published in peer-reviewed journals and Greek dissertations from 2015-2020. It focuses on collaboration practices between in-service educators and parents in the context of inclusive education in primary and secondary schools. Particularly, the article pinpoints the way teachers and parents collaborate, the factors that enhance successful collaboration, and finally the obstacles that hinder effective cooperation. The analyses showed various levels of parental involvement depending on the type of school studied. More specifically, in exemplary schools, teachers and parents seem to build effective collaborative relationships as they apply holistic collaborative and communicative practices. In the other schools studied, communication is usually limited to mandatory meetings, the main subject of which is the behavior of students. Moreover, the review illustrates a variety of barriers that hinder teacher-parent partnerships with the predominant obstacle being lack of time. Subsequently, it highlights the need for specific factors that strengthen successful collaboration between parents and teachers. Finally, this review indicates the need for additional research to explore specific strategies that educators and families could promote to achieve effective collaboration.
\end{abstract}

Keywords: Inclusive education, collaboration, teacher-family, obstacles.

DOI: $10.7176 / \mathrm{JEP} / 12-6-05$

Publication date: February $28^{\text {th }} 2021$

\section{Introduction}

In recent years, the education of students with special educational needs has gradually led to the respect and acceptance of diversity and the promotion of the inclusion of these students in typical educational environments (Bryant, Smith \& Bryant, 2008). Thus, inclusion processes aim to treat all students as equal members of the educational community by limiting their exclusion from the curriculum and other social activities of the school (Farrell \& Ainscow, 2002). Therefore, the family of children with special educational needs is called to take an active role in the educational process. Hence, teachers-family collaboration is regarded as a starting point in educational practices and as a keystone for successfully meeting the needs of children with learning disabilities (Lalvani, 2015). Successful collaboration has a beneficial effect on the performance, attendance, and behavior of students but also on the quality of the services they receive (Chen \& Gregory, 2011; Simpkins et al., 2006). Parental cooperation with the school is necessary not only for parents to better understand how the school works in terms of structure and organization (Cotton, 2000) but also to consult, exchange information, and participate actively for a more effective education for their child (Epstein,2001; Hendersen \& Mapp, 2002). Therefore, this article examines, -through an international literature review the way teachers and parents collaborate- the factors that enhance successful collaboration and the obstacles that hinder effective cooperation.

Research regarding family-educator collaboration has revealed various common themes related to best practices that educators should implement for a successful collaboration. Initially, educators should be reliable, show care for their students and honor each family's language, ethnicity, and culture (Fish, 2008; Ford et al., 2016; Friend \& Cook, 2016; Solone et al., 2020). Additionally, mutual respect and trust between teachers and parents act as a catalyst for students' best results (Solone et al., 2020). Subsequently, they should acknowledge families as experts on their children, work together to develop goals and solutions, assign responsibilities, and engage them in shared decision making (Friend \& Cook, 2013). Besides, teachers should collect all necessary information about the background and learning needs of the student with the aim of a more effective adaptation of teaching (Kokaridas et al., 2008; Schwab, Sharma, and Hoffmann, 2019). Essential collaboration, however, is critical for planning individualized education programs, certain educational activities for children with disabilities and the development of individualized learning objectives (Fish, 2008; Leyser \& Kirk, 2011; Tucker 
and Schwartz, 2013).

Furthermore, systematic communication is another important parameter for successful collaboration. Educators should communicate with parents promptly using communication methods that work for each family (Solone et al., 2020). Particularly, communication in the school context consists of two types, one-way or twoway communication (Berger, 2008). With one-way communication, schools inform parents about events, activities, or their children's progress using letters, newsletters, report cards, and websites. Whether, two-way communication occurs when teachers and parents talk to each other, exchange views through telephone calls, home visits, parent-teacher conferences, and other school-based community programs (Graham-Clay, 2005).

However, the collaboration process between schools and parents or caregivers in the context of special education oftentimes proves to be difficult (Mereoiu et al., 2016). Many parents feel unwelcome and uncomfortable participating in their children's education (Fish, 2006) or perceive themselves as passive recipients of professional decisions since their voices are not heard (Solone et al., 2020). Moreover, many studies have revealed that parents feel unprepared to respond to special education jargon as they do not fully understand the terms or issues discussed in the meetings with professionals (Fish, 2006; Francis et al., 2016; Friend \& Cook, 2016) and feel ill-equipped to attend to the educational needs of their children (Hammond et al., 2008). Another important factor that seems to hinder successful collaboration is the lack of appropriate knowledge and skills from professionals and educators on how to set the stage for a productive family engagement (Ford et al., 2016; Olusegun et al., 2013). Therewithal, another deterrent to parent-teacher communication is the lack of time, as busy parents find it difficult to arrange the right time to be involved in children's education (Patrikakou, 2008).

Thus, a key objective of this review is to examine the way that educators and school communicate with parents or care-givers, in the context of inclusive education and whether they cooperate on a reciprocal basis of respect and trust. Additionally, attempts to summarize the obstacles that make cooperation difficult to provide insight into these problems and highlight teachers' and policymakers' actions that can overcome these potential barriers. This review might provide a more comprehensive investigation into the efficiency of the collaborative practices that educational team members and families of children with special education needs implement in the context of inclusive education.

\section{Search Procedure}

Educational Resource Information Center (ERIC), Google Scholar, Scopus, ProQuest Dissertations \& Theses, and Greek database of Doctoral Dissertations were the databases that were employed in the research for this literature review. The key selection criterion was information from empirical studies about teacher collaboration with families in inclusive education. The search includes only empirical studies published in international, peerreviewed journals and dissertations between 2015 and December 2020. The choice for empirical studies is based on the idea that we wanted to be informed about the views and experiences of those involved: parents and teachers. An additional selection criterion was regular primary and secondary education, meaning the exclusion of studies in early education settings or pre-service teachers.

The following combinations of search terms were used: "teacher-parent cooperation"; "teacher-parent collaboration"; "teacher-parent communication"; "teacher-parent partnership"; "teacher-family partnership". The term "inclusive education" or "inclusion" or "inc*" was then added, resulting in search term combinations such as "teacher-parent inclusive education" or "teacher-parent partnerships inclusive education" etc. The search process eventually led to a total of 10 articles that met the selection criteria.

\section{Overview of Studies}

First, we outline details related to study participants, location, method, and education settings. The results of this examination are presented in Table 1. As depicted in the table, variability existed in the research methods followed and the geographic region where the studies were conducted. Moreover, most of the schools $(\mathrm{N}=4$ out of 10) are characterized as exemplary based on data provided by the researchers (these studies are pointed with "X" in the last column of the table). The participants in three studies are parents and teachers, in four studies only parents, in three studies the participants are parents, teachers, students, and administrators while in one study the number of participants is not mentioned. The findings that emerged from the comprehensive study of the literature grouped into three categories a) content and way of collaboration b) obstacles that hinder familyteacher collaboration and c) factors suggesting for a successful collaboration. 
Table 1.

\begin{tabular}{|c|c|c|c|c|c|}
\hline & Location & Sample(N) & $\begin{array}{l}\text { Method/ } \\
\text { instrument }\end{array}$ & $\begin{array}{l}\text { Education } \\
\text { setting }\end{array}$ & $\begin{array}{l}\text { Exemplary } \\
\text { inclusion } \\
\text { schools }\end{array}$ \\
\hline $\begin{array}{l}\text { (Adams et al., } \\
\text { 2016) }\end{array}$ & Malaysia & $\begin{array}{l}\text { teachers }(\mathrm{N}=95) \text {, } \\
\text { parents }(\mathrm{N}=104) \text {. }\end{array}$ & $\begin{array}{l}\text { Mixed/ } \\
\text { Questionnaire } \\
\text { interviews }\end{array}$ & $\begin{array}{l}\text { Primary } \\
\text { Secondary }\end{array}$ & \\
\hline (Rice, 2018) & Hungary & parents $(\mathrm{N}=9)$ & $\begin{array}{l}\text { Qualitative/ } \\
\text { semi-structured interviews }\end{array}$ & $\begin{array}{l}\text { Primary } \\
\text { Secondary }\end{array}$ & \\
\hline $\begin{array}{l}\text { (Francis et al., } \\
\text { 2016) }\end{array}$ & USA & parents $(\mathrm{N}=58)$ & $\begin{array}{l}\text { Quantitative/ } \\
\text { Focus group }\end{array}$ & $\begin{array}{l}\text { Primary } \\
\text { Secondary }\end{array}$ & $\mathrm{X}$ \\
\hline $\begin{array}{l}\text { (Syriopoulou- } \\
\text { Delli et al., 2016) }\end{array}$ & Greece & $\begin{array}{l}\text { teachers }(\mathrm{N}=171), \\
\text { parents }(\mathrm{N}=50)\end{array}$ & $\begin{array}{l}\text { Quantitative } \\
\text { /Questionnaire }\end{array}$ & Primary & \\
\hline $\begin{array}{l}\text { (Jigyel et al., } \\
2018)\end{array}$ & Bhutan & parents $(\mathrm{N}=26)$ & $\begin{array}{l}\text { Qualitative/open-ended } \\
\text { interviews }\end{array}$ & $\begin{array}{l}\text { Not } \\
\text { mentioned }\end{array}$ & \\
\hline $\begin{array}{l}\text { (Mereoiu et al., } \\
\text { 2016) }\end{array}$ & USA & $\begin{array}{l}\text { parents }(\mathrm{N}=20) \\
\text { teachers }(\mathrm{N}=27)\end{array}$ & $\begin{array}{l}\text { Qualitative / } \\
\text { Focus group (pre- and } \\
\text { post-intervention semi- } \\
\text { structured focus groups) }\end{array}$ & $\begin{array}{l}\text { Not } \\
\text { mentioned }\end{array}$ & \\
\hline $\begin{array}{l}\text { (Lyons et al., } \\
2016)\end{array}$ & Canada & $\begin{array}{l}\text { parents }(\mathrm{N}=18), \\
\text { teachers }(\mathrm{N}=26), \\
\text { students }(\mathrm{N}=16), \\
\text { principals }(\mathrm{N}=8)\end{array}$ & $\begin{array}{l}\text { Qualitative/ semi- } \\
\text { structured interviews }\end{array}$ & Primary & $\mathrm{X}$ \\
\hline $\begin{array}{l}\text { (Minsih et al., } \\
2020)\end{array}$ & Indonesia & $\begin{array}{l}\text { parents, } \\
\text { teachers, } \\
\text { students, } \\
\text { principal }\end{array}$ & $\begin{array}{l}\text { Qualitative/ case study } \\
\text { (observations, interviews) }\end{array}$ & Primary & $\mathrm{X}$ \\
\hline $\begin{array}{l}\text { (Papanikolaou, } \\
\text { 2018) }\end{array}$ & Greece & $\begin{array}{l}\text { parents }(\mathrm{N}=18), \\
\text { teachers }(\mathrm{N}=26), \\
\text { students }(\mathrm{N}=16), \\
\text { principals }(\mathrm{N}=8)\end{array}$ & $\begin{array}{l}\text { Quantitative/ } \\
\text { Questionnaire }\end{array}$ & Primary & \\
\hline $\begin{array}{l}\text { (Wong et al., } \\
2015)\end{array}$ & Singapore & parents $(\mathrm{N}=13)$ & $\begin{array}{l}\text { Qualitative/ } \\
\text { semi-structured interviews }\end{array}$ & Secondary & $\mathrm{X}$ \\
\hline
\end{tabular}

3.1 Content and way of collaboration

Reviewing the literature devoted to the content and the way of collaboration between parents and teachers, the first source of research was Francis et al. (2016) who highlighted the perceptions of parents of children with and without disabilities, about factors that facilitate trusting family-professional partnerships. The study reported qualitative focus group data from research conducted in six exemplary schools in the United States of America. Parents described the attributes of their partnerships with educators and other school staff, including (a) communication, (b) respect, (c) commitment, and (d) professional competence. The comments related to communication were about modality, reciprocity, frequency, and cultural sensitivity in cases where families are from diverse racial/ethnic backgrounds, are new to the school, and/or speak a language other than English. All parents expressed the importance of frequent and informal communication in matters concerning the difficulties or challenges encountered by students. The preferable ways of communication are oral communication (i.e., phone calls, in-person talks before or after school, parent-teacher meetings) and written communication (i.e., home-school journals, emails, text messages, photographs, newsletters, and student plans). Participants in the focus groups discussed the importance of professionals demonstrating respect through action and communication and indicated that professionals' empathy, sensitivity, compassion, and kindness toward students helped build trusting partnerships with families. Participants discussed how teachers and other staff met student needs by crafting individualized strategies, met students at their current levels, and employed "outside of the box strategies" to address unique academic, behavioral, social, and emotional needs. Finally, parents stressed the importance of educators listening to them and taking their opinion into account. As a result of being respected by educators, parents perceive themselves as valued partners in educational decision-making for their children, feel that their contributions and personal investments are appraised and that establish positive differences in the school community.

A mixed-method study in Malaysia (Adams et al., 2016) showed that all interviewed parents were satisfied with the frequent attempts by teachers to communicate through face-to-face meetings, WhatsApp, and letters 
rather than just limit the communication attempt to just a phone call. Teachers stated that their frequent meetings with parents are the only way for them to understand the needs of the child, while at the same time emphasize their willingness to be informed by the parents on the best practices and strategies to guide the SEN students. This information will help teachers to adjust their teaching and meet the objectives determined for each student.

In their qualitative research in Bhutanese schools, Jigyel et al. (2018) found that few parents, particularly the urban mothers, had consistent communication and collaboration with teachers daily or three to four times a week and the issues of their communication were about learning of daily living skills, social skills, and managing behavior. All the other parents reported that communication between them and Special Educational Needs Coordinator and other Special Educational Needs teachers was limited to two or three meetings a month and only when they were asked for a meeting or if they were invited to attend sports activities and excursions. It is worth noting that these parents do not meet at all with the rest of the school staff since, as they say, they did not deal with their children.

Another case study (Minsih et al., 2020) at an exemplary inclusive school in Indonesia, showed that collaboration with parents is one of the determining components in the success of the implementation of inclusive education. As a form of family-school cooperation, it is included: (1) Communication book and Class Journal (2) Student Guardian Forum (ForMil) (3) Home visit (4) Active school communication with students' parents in the form of social media networks and special friendships for parents with special needs. It is worth mentioning that researchers make special reference to the benefits of home visit activities as it is a unique opportunity to interact with families in an informal setting. Furthermore, home visit allows them to enhance their knowledge about children's behavior at home and family background.

The next findings concern a professional learning intervention (Mereoiu et al., 2016) on parents and special educators' perceptions of collaboration. Participants in the professional focus groups recognized that before the training period communication and collaboration between parents and teachers was not effective because it was not systematic and they found it more difficult than expected. After the training, participants realized how much valuable information families have to share and how this information can help them rebalance the partnership by making the families' voices heard. Before the intervention process, parents were more passive listeners relying on the opinion of the special educators while after the end they acquired a more active role as their opinion and experiences were heard by the experts. All participants agreed on the importance of sharing information by families and that the shared decision-making process helps to avoid conflict situations and achieve positive results in improving student performance.

Syriopoulou-Delli et al. (2016) carried out quantitative research in order to empirically investigate and evaluate the key views on the critical collaboration between Greek teachers and parents of children with ASD on educational issues. One of the research findings regarding the content of collaboration revealed that communication between teachers and parents mainly concerns information about children's behavior and their academic progress and less about developing children's skills or managing special difficulties.

Results from a qualitative study (semi-structured interviews) in two exemplary Singaporean schools (Wong et al., 2015) brought to light that communication between home and school is infrequent and it occurs when it is necessary and especially when students are in trouble. Beyond their communication to the biannual parentteacher conferences, parents notice no need to step into the boundaries of the school while educators handle communication with parents as a last resort to rectify outstanding problems.

Rice (2018) in her qualitative study in Hungarian schools found that parents were disappointed with teachers' lack of communication. Furthermore, parents stressed that they had no interaction with teachers to discuss their children's problems and their cooperation was characterized as one-sided or nonexistent.

In contrast, the research of Lyons et al. (2016), which was conducted in four selected (after a thorough survey) inclusive schools in Canada revealed that communication between parents and teachers was open and honest. Additionally, parents stated that they have an active role in developing goals for their child but also in the decision-making process while there is reciprocity in sharing information on effective strategies.

Results from a quantitative research in Greece (Papanikolaou, 2018) showed that cooperation between parents and teachers is apparent since the physical contact of parents with teachers occurs within the framework of their obligations (events, annual briefings) while parents rarely participate in committees and school boards. Concerning the content of their collaboration, the parents are willing to provide information about the special educational needs of the child and they often ask to be informed about the services that can assist themselves and their child. When they are willing to work together on how to educate the child, they develop teaching objectives with the teaching team and jointly evaluate issues related to his / her performance. Although teachers listen to parents' wishes and suggestions, they seldom adapt their teaching or inform the parents about their teaching methods. Thus, while teachers theoretically accept the value of collaboration, on a practical level they realize that their plans are different. Besides, parents reported that because of their professional obligations or business activities, occasionally attend parent-teacher meetings. 


\subsection{Obstacles that hinder family-teacher collaboration}

Through the review of the literature, some inhibitors of communication and cooperation between parents and teachers emerged. According to Papanikolaou (2017), time seems to be the most vital obstacle as both parents and educators agree that the lack of time and the inability to meet are crucial factors in their collaboration. In addition, parents reported that because of their professional obligations or business activities, occasionally attend a parent-teacher meeting (Jigyel et al., 2018; Minsih et al., 2020; Papanikolaou, 2018). What is more, teachers are unable to meet parents as they are continuously confronted by various demands and responsibilities such as co-curricular activities, administrative duties, and multiple initiatives instigated by the Ministry of Education (Wong et al., 2015).

Examining the constraints of teachers - parents' collaboration, Mereiou (2016) revealed that frequently parents feel intimidated by the use of professional jargon. Often teachers and experts use documents that are full of discipline-specific concepts, terminology, and acronyms, making it challenging for people who have not had similar training or extensive experience in special education to understand them (Solone et al., 2020). Mereiou (2016) also underlined teachers' inadequate awareness of the needs of culturally diverse families. Teachers in all focus groups highlighted the importance of understanding the cultural differences as this might influence parent participation. For instance, parents from some cultures hesitate to disagree or criticize teachers, which in turn might prevent them from being able to disagree and share their position in that sense. In addition, participants commented on how different family structures or backgrounds may encounter barriers to engaging in the educational process.

In relation to home visits, Minsih et al. (2020) pointed out that there are many obstacles in implementing the program due to lack of time. The latter also has its weaknesses that require a lot of time for people to handle it as this program is committed to involving all family members in the delivery of interventions. In fact, there are still many families who feel sensitive and cannot be invited to work together in implementing this program. The key is the availability and skills of home visitors to build relationships with families so that any difficulties can be overcome.

\subsection{Factors for a successful collaboration}

Francis et al. (2016) found that a variety of factors enhance trusting partnerships, which are highly interrelated and mutually influential. In particular, a strong school inclusive culture that supports a sense of belonging in a school community favors the feeling of trust among family and school staff. All parents indicated that school principals achieved a culture of inclusion by demonstrating strong, effective leadership; being directly and actively involved; and having great expectations. Also, school administrators can reinforce trust among all stakeholders with specific actions, such as setting high expectations for all students and creating a "welcoming" atmosphere by frequently participating in positive interactions with students, families, and faculty. Moreover, principals are capable of creating opportunities for family involvement in school life and volunteer activities including assisting teachers in the classroom, contacting parents and inviting them to help, and answering new parents' questions.

Jigyel et al. (2018) underlined as significant factors for successful collaboration between parents and teachers the one- way communication such as introductory letters or flyers at the start of the school year, newsletters, communication books, and report cards but more importantly the two-way communication such as telephone calls, teacher-parent conferences, home visits, and various school activities involving parents. Additionally, it should be a regular practice for teachers to provide feedback on the child's holistic development. Lyons et al (2016) also pointed out that teachers and parents should implement collaborative feedback to be partners and build a relationship based on trust without doubting feelings.

Syriopoylou (2016) has found that parents' participation in school activities, continual communication with educational professionals, shared management of students' issues, and a relationship of honesty, trust, and understanding are necessary for effective cooperation. Almost all the teachers stated that frequent contact with parents, at least through a notebook, is a crucial factor for improving the collaboration with parents. Besides, the establishment of a common policy for dealing with students' problems (in honesty between teachers and parents) and relations of mutual trust and understanding are important feedback. Teachers also stressed that their postgraduate training should focus on parents' communication, counseling and collaboration.

\section{Conclusion}

Before concluding, it should be noted that in-service teacher and parent collaboration is not a frequently studied topic in recent years as only a small number of articles (10) met the selection criteria. Regarding the practices, the majority of authors covered in the review refer to the frequency of collaboration between teachers and parents of a student with or without disabilities. In the exemplary schools studied, both teachers and parents communicate on time using one- or two-way methods that work for each family (e.g., phone calls, emails, faceto-face conversations before or after school), while educators are open and honest and respectful of each family's 
language, ethnicity, and culture. In the rest of the studies, communication is usually limited to mandatory meetings during the year or takes place in situations involving student behavior and is often characterized as onesided. Most of the time, the content of collaboration is simplistic and usually concerns information about children's behavior and their academic performance while in exemplary schools, teachers and parents work as a team to develop goals and solutions - engage in shared decision making and acknowledge families as experts on their children.

Nevertheless, several obstacles appear when teachers and parents are trying to collaborate. The majority of respondents who participated in the studies agreed that lack of time due to the professional obligations of the parents and the administrative duties of the teachers is one of the most important barriers. Moreover, many parents feel unwelcome and uncomfortable participating in their children's education as they are unequipped to attend to the educational needs of their children and feel unprepared to respond to special education jargon.

The majority of the authors suggest several factors that can implement successful collaboration between parents and teachers. A strong inclusive school culture, frequent two-way communication, equity, trust, and respect are some of the several common themes related to best practices that emerged through the review of the aforementioned studies. Subsequently, teacher training in inclusive education seems to be another factor that to have a positive effect on creating positive collaborative environments.

Overall, the practices and content of the collaboration between parents and teachers, in the context of inclusive education, vary depending on the type of school studied. Recent empirical studies mainly concern exemplary schools where the beneficial results of the collaboration are reflected in students' outcomes. It is recommended that further research should be undertaken in analyzing and comparing the collaboration practices from a variety type of schools (exemplary or not schools). It could also explore how postgraduate education can help improve collaborative practices. In addition, future researchers should explore specific strategies that educators and families could promote to achieve successful collaboration, as the latter is one of the most important elements to ensure effective inclusive education.

\section{References}

Adams, D., Harris, A., \& Jones, M. S. (2016). Teacher-Parent Collaboration for an Inclusive Classroom: Success for Every Child. Teacher-Parent Collaboration for an Inclusive Classroom: Success for Every Child., 4(3), $58-71$.

Berger, E. H. 2008. Parents as Partners in Education: Families and Schools Working Together. 7th ed.New Jersey: Merrill Prentice Hall.

Bryant, D. P., Smith, D. D., \& Bryant, B. R. (2008). Teaching students with special needs in inclusive classrooms. New York, NY: Pearson Education)

Chen, W., \& Gregory, A. (2011). Parental involvement in the prereferral process: Implications for schools. Remedial \& Special Education, 32, 447-457 https://doi:10.1177/0741932510362490

Epstein, J. L. (2001). School, family, and community partnerships: Preparing educators and improving schools. Boulder CO: Westview.

Farrell, P., \& Ainscow, M. (Eds.). (2002). Making Special Education Inclusive: From Research to Practice (1st ed.). David Fulton Publishers. https://doi.org/10.4324/9780203437261

Fish, W. W. (2008). The IEP meeting: Perceptions of parents of students who receive special education services. Preventing School Failure: Alternative Education for Children and Youth, 53, 8-14.

Fish, W. W. (2006). Perceptions of parents of students with autism towards the IEP meeting: A case study of one family support group chapter. Education, 127, 56-68.

Ford, B. A., Vakil, S., \& Boit, R. J. (2016). Family engagement within inclusive settings. Advances in Special Education, 32, 75-98. https://doi.org/10.1108/S0270-401320160000032006

Francis, G. L., Blue-banning, M., Turnbull, A. P., Hill, C., Shana, J., Gross, J. M. S., Francis, G. L., Bluebanning, M., Turnbull, A. P., \& Haines, S. (2016). Division on Autism and Developmental Disabilities Culture in Inclusive Schools : Parental Perspectives on Trusting Family-Professional Partnerships Published by: Division on Autism and Developmental Disabilities Stable URL: https:/www.jstor.org/stable/. Education and Training in Autism and Developmental Disabilities, 51(3), 281-293.

Friend, M., \& Cook, L. (2013). Interactions: Collaboration skills for school professionals (7th ed.). Boston, MA: Pearson.

Friend, M. P., \& Cook, L. (2016). Interactions: Collaboration skills for school professionals. Boston, MA: Pearson.

Graham-Clay, S. (2005). Communicating with Parents: Strategies for Teachers. The School Community Journal, $15(1), 117-129$.

Hammond, H., Ingalls, L., \& Trussell, R. P. (2008). Family members' involvement in the initial individual education program (IEP) meeting and the IEP process: Perceptions and reactions. International Journal about Parents in Education, 2, 35-48. 
Hendersen, A. T., \& Mapp, K. L. (2002). A new wave of evidence: The impact of school, family and community connections on students' achievement. Austin, TX: Southwest Educational Laboratory.

Jigyel, K., Miller, J. A., Mavropoulou, S., \& Berman, J. (2018). Parental communication and collaboration in schools with special educational needs (SEN) programmes in Bhutan. International Journal of Inclusive Education, 22(12), 1288-1305. https://doi.org/10.1080/13603116.2018.1426053

Kokaridas, D., Vlachaki, G., Zournatzi, E., \& Patsiaouras, A. (2008). Parental Attitudes Regarding Inclusion of Children with Disabilities in Greek Education Settings. Electronic Journal for Inclusive Education, 2(3), 113.

Lalvani, P. 2015. "Disability, Stigma and Otherness: Perspectives of Parents and Teachers." International Journal of Disability, Development and Education 62 (4): 379-393.

Leyser, Y., \& Kirk, R. (2004). Evaluating inclusion: An examination of parent views and factors influencing their perspectives. International Journal of Disability, Development and Education, 51(3), 271-285.

Lyons, W. E., Thompson, S. A., \& Timmons, V. (2016). We are inclusive. We are a team. lets just do it': Commitment, collective efficacy, and agency in four inclusive schools. International Journal of Inclusive Education, 20(8), 889-907. https://doi.org/10.1080/13603116.2015.1122841

Mereoiu, M., Abercrombie, S., \& Murray, M. (2016). One step closer: Connecting parents and teachers for improved student outcomes. Cogent Education, 3(1), 1-19. https://doi.org/10.1080/2331186X.2016.1243079

Minsih, Mujahid, I., \& Suparno. (2020). Supporting system in inclusive education: A case study from Indonesian elementary school. International Journal of Scientific and Technology Research, 9(3), 5256-5261.

Olusegun, A., Sourav, M., \& Johnson, N. (2013). Implementation of inclusive education: Do parents really matter? Specijalna Edukacija i Rehabilitacija, 12(3), 373-401. https://doi.org/10.5937/specedreh12-4370

Papanikolaou, G. (2018). Indicators of quality of inclusive education programs for students with disabilities and / or special educational needs (Doctoral dissertation,Aristotle University of Thessaloniki). http://hdl.handle.net/10442/hedi/44747.

Patrikakou, E. N.(2008). The Power of Parent Involvement: Evidence, Ideas, and Tools for Student Success. USA: Center on Innovation \& Improvement.

Rice, N. (2018). Parent perspectives on inclusive education in Budapest. European Journal of Special Needs Education, 33(5), 723-733. https://doi.org/10.1080/08856257.2017.1410325

Schwab, S., U. Sharma, and L. Hoffmann.( 2019). "How Inclusive are the Teaching Practices of My German, Maths and English Teachers? - Psychometric Properties of a Newly Developed Scale to Assess Personalisation and Differentiation in Teaching Practices." International Journal of Inclusive Education 116. https://doi:10.1080/13603116.2019.1629121.

Simpkins, S. D., Weiss, H. B., McCartney, K., Kreider, H. M., \& Dearing, E. (2006). Mother-child relationship as a moderator of the relation between family educational involvement and child achievement. Parenting: Science \& Practice, 6, 49-57. https://doi:10.1207/s15327922par0601 2

Solone, C. J., Thornton, B. E., Chiappe, J. C., Perez, C., Rearick, M. K., \& Falvey, M. A. (2020). Creating collaborative schools in the united states: A review of best practices. International Electronic Journal of Elementary Education, 12(3), 283-292. https://doi.org/10.26822/iejee.2020358222

Syriopoulou-Delli, C. K., Cassimos, D. C., \& Polychronopoulou, S. A. (2016). Collaboration between teachers and parents of children with ASD on issues of education. Research in Developmental Disabilities, 55, 330345. https://doi.org/10.1016/j.ridd.2016.04.011

Tucker, V., \& Schwartz, I. (2013). Parents' perspectives of collaboration with school professionals: Barriers and facilitators to successful partnerships in planning for students with ASD. School Mental Health, 5, 3-14.

Wong, M. E., Ng, Z. J., \& Poon, K. (2015). Supporting Inclusive Education:Negotiating home-school partnership in Singapore. International Journal of Special Education, 30(2), 119-130. 